\title{
BALZAC, Gobseck et autres récits d'argent
}

\section{Lise Sabourin}

\section{CpenEdition \\ Journals}

Édition électronique

URL : https://journals.openedition.org/studifrancesi/44014

DOI : 10.4000/studifrancesi.44014

ISSN : 2421-5856

\section{Éditeur}

Rosenberg \& Sellier

Édition imprimée

Date de publication : 1 juin 2021

Pagination : 226

ISSN : 0039-2944

\section{Référence électronique}

Lise Sabourin, « BALZAC, Gobseck et autres récits d'argent », Studi Francesi [En ligne], 193 (LXV | I) | 2021, mis en ligne le 01 juillet 2021, consulté le 15 octobre 2022. URL : http://journals.openedition.org/ studifrancesi/44014; DOI : https://doi.org/10.4000/studifrancesi.44014

Ce document a été généré automatiquement le 15 octobre 2022.

\section{(c) (1)}

Creative Commons - Attribution - Pas d'Utilisation Commerciale - Pas de Modification 4.0 International - CC BY-NC-ND 4.0

https://creativecommons.org/licenses/by-nc-nd/4.0/ 


\title{
BALZAC, Gobseck et autres récits d'argent
}

\author{
Lise Sabourin
}

\section{RÉFÉRENCE}

BALZAC, Gobseck et autres récits d'argent, éd. A. Péraud, Paris, Gallimard, 2019, «Folio

classique», $447 \mathrm{pp}$.

1 L'intérêt de ce volume est de regrouper cinq récits balzaciens liés à l'argent, au sens moderne du terme, non pas de convoitise ou de thésaurisation, mais par sa circulation qui impacte les relations personnelles et suscite une dynamique sociale. Débiteur constant, entrepreneur hasardeux, Balzac était bien placé pour analyser avec perspicacité et méfiance à la fois les mécanismes de cet instrument de la sociabilité contemporaine. La préface d'Alexandre Péraud, intitulée «L'humanité à hauteur d'argent» (pp. 7-50), en montre le caractère essentiel à son génie: l'argent n'est pas pour lui un élément du décor ou d'ancrage contextuel, il raconte le siècle de manière à la fois épique, tragique et fantasmagorique.

2 Si les grandes fresques que sont César Birotteau, La Maison Nucingen, Illusions perdues, Le Médecin de campagne, Le Curé de village, Eugénie Grandet décrivent bien la naissance du monde capitaliste, les cinq récits réunis ici n'en sont pas moins révélateurs. Ils peuvent de plus, en ce format de poche, et grâce au dossier (pp. 383-446, comprenant biographie de Balzac, notice sur l'histoire des textes, sur l'argent balzacien, titres des chapitres du Député d'Arcis, bibliographie, notes), permettre à des élèves ou des étudiants d'entrer par une porte plus restreinte dans l'univers mental balzacien en offrant plusieurs types savoureux.

3 Gobseck (pp. 53-131), la plus célèbre de ces nouvelles, révèle le triste sort de l'usurier millionnaire exploiteur des intrigues liées aux mésalliances recommandées par les usages sociaux. L'Illustre Gaudissart (pp. 133-189) donne le portrait du représentant de commerce de génie, sauveur de l'entreprenant mais téméraire César Birotteau. 
Gaudissart II (pp. 191-207), son fils, sait vendre ce qui n'existe pas, marchand de vent contemporain avant la lettre. Un homme d'affaires (pp. 209-236) crée le prototype du roi de la dette contraint à remboursement, observé par une société habituée pourtant à vivre aux crochets de ses créanciers. Le Député d'Arcis (pp. 237-380) développe la veine liée à la corruption en campant un commissaire politique tripatouillant des élections.

4 Voilà comment le monarchiste conservateur et réactionnaire qu'était Balzac a réussi à décrire, à travers luttes, rivalités, violences, prédation, oscillant entre comique et étrangeté, les mécanismes du capitalisme naissant au point de constituer une référence pour l'idéologie marxiste qu'il aurait évidemment récusée dans ses conséquences. 